Fecha de recepción: marzo 2012 Fecha de aceptación: junio 2012 Versión final: junio 2013

\section{Renacimiento y naturalización del gusto. Una paradoja de la moda italiana}

\author{
Simona Segre Reinach *
}

\begin{abstract}
Resumen: El regreso al Renacimiento, fundamental de un cierto discurso occidental sobre el vestir, que se reanudó nuevamente durante los años ochenta del siglo XX para explicar la moda, indica no tanto un intento por conocer la historia de un fenómeno que se desarrollaría más tarde, cuanto la necesidad de partir de un período en el que Italia tenía el liderazgo del gusto. No se trata sólo del deseo de volver a los orígenes, sino también de poner entre paréntesis una Italia que, a partir del siglo XVII, ve disminuir progresivamente su posición privilegiada en Europa. Durante los años 80, sin embargo, la explicación del Renacimiento resalta particularmente, dado el carácter revolucionario del nuevo sistema, posteriormente imitado por otros países y otras modas y por la estrecha relación entre moda y sociedad de consumo, entre estética e industria.
\end{abstract}

Palabras clave: estilistas - gusto - herencia estética - occidente - prêt à porter - Renacimiento.

[Resúmenes en italiano, inglés y portugués en las páginas 156-157]

(*) Antropóloga cultural. Trabaja como Profesor adjunto en la Università di Bologna. Forma parte del Board of Advisors della rivista Fashion Theory. Colabora con el centro para el estudio de la moda de la Universidad Católica de Milán (Modacult) y con el centro Moda Immagine Consumi (Mic) de la Universidad Estatal de Milán.

El éxito de la moda italiana en el mundo está vinculado tradicionalmente con el concepto italiano de "bello": "Una belleza que rodea al niño desde su infancia, cuyas raíces hay que buscar en los frescos, pinturas y mosaicos que se encuentran en las catedrales de las innumerables ciudades-estado"(Alberoni, 1984).

Niños hipotéticos, por supuesto, niños felizmente ignorantes de la especulación de los años 60, que han vivido sólo en plazas antiguas, que han estudiado con provecho historia del arte, latín y griego, niños que nunca han visto la televisión. A falta de una justa apreciación de los aspectos de la cultura popular y de comunicación característicos de la moda, como de su caracterización de industria cultural (Ricchetti y Cietta 2006), muchas de las consideraciones sobre la moda quedaron atrapadas entre la búsqueda de sus "raíces históricas" -orientadas a fundar una especie de "sociología de la estética italiana", inevitablemente relacionada a la edad de oro del Renacimiento italiano- y los estudios sectoriales, que por muy detallados y orientados, no siempre han tenido en cuenta la dimensión social y cultural del fenómeno de la moda, es decir, 
su profunda integración en los lenguajes del capitalismo tardío. Faltando, así, la formulación de una "teoría de la moda como teoría de la cultura" (Calefato 2004).

Excepto para el estudio de los contenidos de la moda como un factor de diferenciación de los productos, los economistas casi han abandonado los estudios de ésta, vista como un epifenómeno de poca importancia económica (Ricchetti y Cietta 2006, p. 26). La moda, en virtud de su éxito, no podía no ser leída como una expresión de aquella cultura clásica, de aquella historia del arte, simplemente de aquella historia y cultura, en las que, incluso en tiempos recientes, la mayoría de los intelectuales identificaban tanto un motivo de orgullo, cuanto un baluarte contra los excesos de la modernidad y una fuente de inspiración por un producto culto y elitista. Se ha preferido entender la moda como algo que Italia era capaz de hacer, casi por don divino o por naturaleza, dependiendo de las circunstancias y puntos de vista, un "desde siempre y para siempre", en lugar de considerar los aspectos innovadores en la historia de la moda. La fortuna extraordinaria de la moda se atribuye a una "actitud" que, brotando de la cultura del pasado, se convierte en un instinto natural, practicando una especie de naturalización del gusto.

Nuestro estilo de vida nació del instinto, cualidad que se puede definir como una segunda naturaleza de los italianos y que viene de la costumbre de vivir en medio del arte y la cultura (Fiorentini Capitani, en Vergani 1992, p. 92). La creatividad italiana se basa por lo tanto, en nuestra historia y en nuestro patrimonio cultural. Estos elementos se pueden definir como "efecto Renacimiento" (Boselli en Codeluppi y Ferraresi 2007, p. 93). También Gianfranco Ferré (1944-2007), miembro de la generación que contribuyó a crear y difundir a nivel internacional el concepto del Made in Italy, se expresa de esta manera, en un libro dedicado a los jóvenes futuros diseñadores:

Nuestro prêt à porter, diría incluso nuestro estilo, nuestro concepto moderno de elegancia, nació en un contexto donde las artesanías tradicionales, el mismo artesanado que en los talleres de las ciudades del Renacimiento daba al mundo los frutos maravillosos y únicos, fue capaz de convertirse en una moderna estructura de producción, altamente especializada y tecnológica. Y esta estructura que, a finales de los años sesenta, será el punto de referencia privilegiado, background ideal e insustituible de nuestro design de calidad. El diseño de moda italiano, el Made in Italy, está estrechamente vinculado a este tipo de producción: por un lado tejidos y materiales sin precedentes en el mundo, por el otro una feliz fusión entre hombres y producción (Ferré 1996).

La idea del saber hacer italiano de tipo artesanal y textil característico de la Edad Media, floreció durante el Renacimiento, en la búsqueda de la belleza como un rasgo antropológico constante de Italia, generando un hilo conductor que une a Lorenzo de Medici y a Giorgio Armani, con la intención de "dignificar" la moda, emancipándola de los aspectos textiles (técnicos) y prácticos para hacerla ascender a materia digna, es decir, humanística. El recurso al Renacimiento se vuelve explícito a partir del siglo XIX.

En particular hacia finales del siglo XIX, como parte de la construcción de un lenguaje estilístico nacional, se propone en repetidas ocasiones como un modelo de identidad italiana el Renacimiento, considerado el momento más grande de la cultura artística de nuestra cultura 
y opuesto al regionalismo italiano, por un lado, y a los modelos internacionales, neogótico y floral, por el otro (Fortunati y danés, 2005, p. 73).

Frecuentemente encontramos la relación entre moda y Renacimiento, desde inicios del siglo XX hasta nuestros días. Basta pensar en Rosa Genoni y el vestido inspirado en la Primavera de Botticelli o en la moda de los años Treinta, cuando la cuestión de la identidad era "urgente y sincera" (Paulicelli 2004, p. 6). Pensemos también en Germana Marucelli, en las imágenes de los años Cincuenta, cuando se utilizaba como "hilo conductor de la Alta moda italiana, y también de algunas expresiones de la moda" (Butazzi, 1987, p. 7) o cuando se afirmaba que "las colecciones italianas, por primera vez llevadas a la atención de todo el mundo, traducían en la línea y en el corte la herencia del patrimonio artístico del Renacimiento"1. La atención a la belleza como rasgo antropológico italiano, buen gusto, medida, sentido de la proporción, presente en una mezcla de naturaleza y cultura absolutamente única, es invocada para explicar la 'vocación' italiana a la moda (Squicciarino, 1986). ${ }^{2}$

Historia y orgullo nacional, en primer lugar, luego estereotipo internacional, oposición nacional a los localismos regionales o también a su complementariedad. Pero no sólo. La modernidad del siglo XIX, burguesa e industrial, de centros tales como Londres y París, verdaderas metrópolis del siglo XIX, no pertenece a ninguna de las ciudades italianas, ni en general a Italia, cuya unificación se remonta a 1861, y que permanece respecto al desarrollo industrial, siempre por detrás de Francia, Inglaterra y los Estados Unidos. Incluso al comienzo de la nueva cultura de consumo de la sociedad de masas de la segunda mitad del siglo XX, Italia es diferente de otros países europeos. A diferencia de aquellos, una vez en la

aculturación del consumo de masas, preparada por tres aculturaciones anteriores, la de la revolución burguesa y la de la primera revolución industrial en Italia no se había logrado hacer que los bienes superfluos fueran un hecho positivo (como objetivamente debería ser) (Pasolini 1970, cit. en Colaiacomo, 2007, p. 49).

El uso de la época del Renacimiento, período, además, significativo en la fundación de un discurso occidental sobre el vestir, retomado una vez más durante los años Ochenta del siglo XX para explicar la moda, es signo, no tanto de un intento de conocer el pasado de un fenómeno que se desarrollaría, dirigido a "revisar 'las circunstancias' que hicieron posible una cierta visión del pasado" (Paulicelli, 2006, p. 12), cuanto de la necesidad de anclarse en un momento en el que Italia tenía el liderazgo del gusto. No se trata sólo del deseo de "renovar la historia de Italia como una nación de origen noble" (Fortunati y Danese, 2005, p. 11), sino también de poner entre paréntesis a una Italia que, desde el siglo XVII, ve disminuir progresivamente su papel en Europa. Durante los años 80, sin embargo, la explicación del Renacimiento aparece particularmente sorprendente, dado el carácter revolucionario del nuevo sistema, luego imitado por otros países y otras modas y por la estrecha relación entre la moda y la sociedad de consumo, la estética y la industria.

De la síntesis entre el mundo de la moda y el mundo de la industria nació, entonces, ese complejo aparato de actividades de producción y servicios que hoy se denomina industria de la moda, pero que también podría llamarse, por sus orígenes italianos, el modelo de la moda made in Italy (Ricchetti y Cietta, 2006, p. 25). 
A pesar de que se refiere, aparentemente, a un ámbito exclusivo y excluyente, cuya comunicación, por ejemplo, va dirigida a profesionales y a unos pocos elegidos, el prêt à porter es en realidad un fenómeno de masas. Su lenguaje y su comunicación, confundiendo significante y significado, ha contribuido a ocultar la novedad que, en cambio, ha significado y para la cual se ha impuesto: la posibilidad de una estética industrial, un producto con una capacidad sugerente y seductora comparable a la alta moda, accesible como la moda ready. Emanuela Mora escribe al respecto:

La doble alma de la moda italiana, al mismo tiempo industrial y artística, influye en el desarrollo del sistema moda, que encarna estructuralmente la dialéctica entre el arte y el producto de consumo, entre cultura alta y cultura popular, entre la élite y la masa (o al menos la dialéctica entre diferentes fracciones de la élite), modificando, por ende, la naturaleza misma del producto de moda y haciendo de esta última una rama del universo más amplio de la industria cultural (Mora,2004, p. 13).

La moda de los diseñadores, por lo tanto, representa un momento de considerable innovación en la historia de la moda moderna. Nicola White demuestra cómo el prêt à porter italiano no es un fenómeno surgido de la nada, sino que tiene sus raíces entre 1945 y 1964 durante el primer boom económico italiano, cuando la moda italiana nació gracias a la ayuda de Estados Unidos (White, 2000, pp. 1-7).

Si desde el punto de vista de la capacidad de producir prendas de vestir puede prevalecer una hipótesis de continuidad -el prêt à porter ciertamente no surge por casualidad, sino que es el resultado de una evolución del sector textil y de la industria- en términos de significados que la moda asume, se trata, sin embargo, de un fenómeno radicalmente nuevo. El prêt à porter nace en 1949 en Estados Unidos como ready to wear industrial y desarrollado, en Francia encuentra a continuación, además del nombre con el que se afirma, un significado ulterior como "una moda de medio lujo, de costo relativamente bajo, de corte y sabiduría muy personalizados" (Ricca, 1969 cit. en París, 2006, p. 423), y conoce, finalmente, un cambio radical en Italia, donde una colaboración más eficaz entre la industria y el estilo lo transforma en made in Italy.

Durante los años Ochenta tiene lugar una solución de continuidad en las políticas del gusto. Y los cambios en el gusto, como enseña Pierre Bourdieu, (2001), pueden indicar cambios en la 'posición' del individuo en la sociedad. Uno de los aspectos más destacados de la moda italiana de los estilistas en el que se basa su propia modernidad consiste, precisamente, en la disolución del gusto burgués y de las prácticas relacionadas con él. Gianni Versace -el rey del glamour- (Buckley y Gundle, 2000, p. 332), quien ha afirmado "Odio el buen gusto", constituye la mejor demostración del nuevo lugar que la moda italiana propone y defiende en la sociedad "post- burguesa" del consumo. El flash trash de Versace indica, precisamente, la distancia de los códigos de la moda burguesa y la entrada de la moda en los códigos de comunicación de masas. Lo que cambia, respecto a los criterios de la vieja elegancia, es el modo de funcionamiento de esta capacidad que en primer lugar es completamente efímera e interna a la lógica de la moda, y en segundo lugar, se transmite principalmente a través de los mecanismos de comunicación de masas y no por otras formas intermedias y de élite de socialización, como era el caso de la 
elegancia (Ugo Vollo, 2003, p. 437). La elegancia entendida como depósito de modas y jerarquías del pasado (Bourdieu, 2001), moda como declaración de pertenencia al presente. Todos los estilistas italianos, en la primera parte de su carrera, y cada uno a su manera, se caracterizan por una revolución de los códigos burgueses dentro de la moda. Incluso Giorgio Armani, a menudo en oposición a Gianni Versace -uno representante del estilo sobrio y "understated", el otro exagerado, excesivo y transgresivo- comenzó su carrera con una gran revolución, la inversión de los códigos masculinos y femeninos, con la feminización del hombre, con el famoso saco roto hecho con tejidos "de mujer", y masculinizando a la mujer, realizando el success dress, el traje overol para la "mujer manager" que debe comunicar autoridad y seducción. Ciertamente, hay que señalar que la moda de los estilistas ha tenido éxito precisamente porque se ha propuesto en una forma única y distintiva en el discurso entre alto y bajo, entre la élite y la calle, ofreciendo su propia versión de la cultura de masas. De instrumento de ostentación burguesa, como era la alta moda francesa, el vestido -con el prêt-à-porter de un estilista- se ha vuelto sobre todo expresivo. De signo de rechazo de los códigos y convenciones sociales, como lo era la anti-moda y la subcultura juvenil de origen anglosajón, se ha vuelto discurso y práctica compartida. La modernidad del sistema de los estilistas no se encuentra tanto en subvertir cuanto en haber contribuido a poner fin a cualquier subversión, anticipándose a lo que sucede en general en la cultura contemporánea, donde se mezclan mercado y contracultura. Como escribe Dick Hebdige muchos años después del estudio pionero sobre las subculturas juveniles en Inglaterra:

La idea misma de la subcultura en contraposición a la cultura dominante no es sostenible de ninguna manera. De hecho hoy, la cultura general está tan impregnada de imágenes a la moda, del estilo y del diseño, que casi se puede decir que tiende ella misma a convertirse en subcultura. Con todas las consecuencias que eso comporta (1990, cit. en Segre Reinach, 2010, p. 63).

A diferencia de lo que ocurrió en Inglaterra, donde la cultura juvenil y la anti-moda se han caracterizado por su agudo contraste respecto de la cultura dominante, como expresión de una contracultura surgida de una tradición particular de movimientos juveniles (los mods, los rockets y todas las subculturas que han precedido y hecho posible la swinging London de los años 60), la moda italiana, años más tarde, cuando las revoluciones habían terminado, se caracteriza por una función mediadora entre dos polos: los jóvenes, la revuelta, la anti-moda por un lado -y la cultura emergente del cuerpo con el retorno, en clave mediática, de una necesidad social de aparecer. A la nueva cultura visual se adhieren tanto los jóvenes como aquellos que habían sido excluídos de los rituales de la alta burguesía del siglo XIX, es decir, la nueva gran clase media en la que confluyen burguesía y proletariado. En Italia, la moda no es, por lo tanto, directamente comparable a una forma de cultura popular, si la entendemos en su aspecto de rechazo de los códigos compartidos por las clases altas. No ha tenido esa dimensión antagonista a la que se refiere Dick Hebdige (1978). Los aspectos más experimentales e innovadores de la moda, que sí los hubo, por un lado no tuvieron una vocación 'en contra' del rasgo juvenil de las culturas anglosajonas, por el otro se encallaron antes de alcanzar la necesaria visibilidad, o permanecieron, en cuanto experimentales, proyectos de 
segmento. Es ésta, por ejemplo, la tesis de Paola Colaiacomo para quien el made in Italy, que ella entiende como una generalización de un éxito, si se investigan a la inversa, justo en aquellos años que formaron la base, los años setenta del siglo XX, emerge como:

El resultado de una obliteración de las búsquedas y los experimentos más radicales e innovadores, que al no lograr romper el bloqueo de la producción industrial, permanecieron, justo en esos mismos años, claustrofóbicamente encerrados en el limbo de un proyecto experimental, llamado "de vanguardia" (Colaiacomo, 2006, p. 7).

La moda de los estilistas italianos, pero en un cierto sentido también la de sus precursores inmediatos -valga el ejemplo de Elio Fiorucci- ha jugado un papel importante en la reconciliación entre la ideología de la anti-moda, basada en el rechazo de la moda como una expresión burguesa, típica de la generación joven y de protesta, y una nueva cultura hedonista basada en el consumo, el cuerpo y el dinero, típica de los años 80 . Lo que se refiere a menudo como la "democratización del lujo", realizada por el prêt à porter italiano respecto a su semejante francés, de luxe, es el efecto de la desaparición gradual de la moda como una expresión de clase y su renacimiento como una forma frecuente de comunicación de la sociedad de masas. Este aspecto "reconciliador", que ha prevalecido después de haber abandonado o no haber expresado lo que pertenecía a proyectos menos conciliadores o más vanguardistas, es fundamental en el éxito de la moda italiana, que se convierte en "hecho en Italia", tanto en Italia como en el extranjero, en la propagación de su lenguaje y de su vocabulario estético. La "creatividad italiana" que en el lenguaje común se asocia al éxito del prêt à porter, reside no tanto en la invención estilística, que sin duda existe, pero que es sólo un aspecto, cuanto en la inserción de "la moda de los estilistas" en el mundo y en la cultura de consumo; en su devenir sinécdoque y metáfora, con la plena aplicación de su lenguaje, de lo visual a lo comercial, integrándolos y haciéndolos inseparables. En este sentido, la moda italiana, entendida como Made in Italy, la moda de los estilistas, ha sido creativa y moderna. No tanto por una "tradición italiana de la belleza" y del estilo, que se utiliza a menudo asumiendo la continuidad con el Renacimiento, sino por su consonancia con el espíritu de su tiempo y su coincidir con una época de intenso cambio social y cultural. Conjunción entre élite y cultura popular, en la disolución de los códigos burgueses que en cambio habían caracterizado la modernidad de París y Londres, la moda de Milán iniciaba un nuevo ciclo de la moda destinada a convertirse en una forma de comunicación de masas. Las shopping bag "diccionarios móviles del consumo" registran puntualmente el cambio: París, Londres, Milán, Nueva York.

De acuerdo con Patrizia Calefato (2007, p. 54) hay dos modos de ver la moda, uno institucional, espectacular y consumista, vinculado a las formas como la alta moda, el mito de la pasarela, de las modelos, y otro más excéntrico, de cultura "alternativa", que representa ideologías en formación y que se manifiesta en look, antimoda y estilos. La primera dimensión es convencional, a veces incluso conservadora, mientras que la segunda, que Calefato define de "mundanidad", es más amplia, menos predecible. Los dos ámbitos, que hoy tienden a estar cada vez más separados, durante los años ochenta han coincidido en gran medida, estimulando el poder comunicativo de la moda que encarna tanto la convención como lo contrario. Sería complejo encontrar una relación entre una primacía cultural o económica de una cultura o nación, y la imposición de un estilo, aunque en una amplia perspectiva el análisis histórico 
haya identificado una relación de este tipo -a la moda española de 1500 y 1600 siguió por ejemplo, la francesa, cuando Francia reemplazó a España como la nación líder en Europa. A corto plazo, las consideraciones son diferentes. Aunque los años ochenta fueron una década positiva para Italia, el segundo boom económico de la posguerra es mayor, por el número de personas implicadas y la intensidad de los cambios en los valores de referencia, al primero, el los años sesenta (tal vez el dato fue amplificado en parte por los medios de comunicación). Por mucho que el país fuera considerado como la cuarta potencia europea- era la época de "superar" a Inglaterra -sería difícil encontrar una primacía italiana de cualquier tipo, ya sea a nivel europeo o internacional, que justificara su liderazgo en la moda. Sin embargo, la moda italiana ha llegado a ser, y en parte lo sigue siendo, una de las pocas ventajas competitivas, tal vez el único rasgo reconocido de un país caracterizado por graves deficiencias económicas y estructurales. Más que expresión de liderazgo nacional, el prêt à porter italiano ha expresado el inicio de esa cultura de la moda como forma ejemplar de comunicación de la sociedad de consumo del capitalismo tardío en el proceso de transnacionalización.

\section{Notas}

1. Una de las principales marcas de moda con sede en el Centergross de Bolonia se llama Renacimiento.

2. Recuerdo una broma que la cineasta Marina Spada en el film Come l'ombra (2006) hace decir a la joven mujer proveniente del este de Europa en busca de fortuna en Milán: "Italia, la tierra de Leonardo da Vinci, Miguel Ángel y Giorgio Armani”.

\section{Referencias Bibliográficas}

Alberoni, F. (1984). L'Italia inventò la moda. Panorama, 22 de octubre.

Boselli, M. (2007). Il tessile-abbigliamento-moda nel mondo. Ieri, oggi, il futuro, en Codeluppi e Ferraresi (2007), La moda e la città. Milán: Carocci, pp. 91-98.

Bourdieu, P. (2001) [1979]. La distinzione. Bolonia: Il Mulino.

Buckley, R.C.V. y Gundle, S. (2000). Flash Trash: Gianni Versace and the Theory and practice of Glamour, in Bruzzi, S.; Church Gibson, P. (a cargo de) (2000). Fashion Cultures, Theories, Explorations and analysis. Londres: Routledge, pp. 331-348.

Butazzi, G. (1987). Prefazione in 2 voll A.A.V.V., I vol., p. 7.

Calefato P. (2007). Mass moda: linguaggio e immaginario del corpo rivestito. Roma: Meltemi. (2004). Lusso. Roma: Meltemi.

Colaiacomo, P. (2007). Pasolini e l'eleganza faziosa. Venecia: Marsilio. (2006). Fatto in Italia. La cultura del made in Italy. Roma: Meltemi.

Ferrè, G. (1996). A un giovane stilista. Milán: Nuove Pratiche.

Fiorentini Capitani, A. y Ricci, S. (1992). Le carte vincenti della moda italiana, en G. Vergani (a cargo de). (1992). La Sala Bianca. Milán: Electa.

Fortunati, L. e Danese, E. (2005). Il made in Italy, Manuale di sociologia, comunicazione, cultura della moda, Vol. III. Roma: Meltemi. 
Hebdige, D. (1983). Sottocultura. Il fascino di uno stile innaturale. Génova: Costa \& Nolan. Mora, E. (2004). Introduzione a D. Crane. Questioni di moda. Milán: Franco Angeli. Muzzarelli, M. G. (2011). Breve storia della moda in Italia. Bolonia: Il Mulino.

Paris, I. (2006). Oggetti cuciti. Milán: Franco Angeli.

Paulicelli, E. (2004). Fashion under Fascism. Oxford-Nueva York: Berg.

Ricchetti, M. e Cietta, E. (2006). Il valore della moda. Milán: Bruno Mondadori.

Segre Reinach, S. (2010). La moda. Un'introduzione. Roma-Bari: Laterza.

Squicciarino, N. (1986). Il vestito parla. Roma: Armando.

Volli, U. (2003). Gusto e cattivo gusto, en Gregory, T. (a cargo de) (2003). Enciclopedia della moda. Roma, pp. 429-440.

\begin{abstract}
Il ricorso al Rinascimento, fondativo di un discorso occidentale sull'abito, ripreso ancora una volta durante gli anni Ottanta del Novecento per spiegare la moda, è indice non tanto di un tentativo di conoscere il passato di un fenomeno che si sarebbe sviluppato, quanto della necessità di ancoraggio a un periodo in cui l'Italia aveva la leadership del gusto. Non si tratta solo del desiderio di ripercorrere le origini ma anche di mettere tra parentesi un'Italia che, a partire dal Seicento, vede progressivamente scemare la sua posizione di privilegio in Europa. Durante gli anni 80, tuttavia, la spiegazione del Rinascimento appare particolarmente stridente, data la rivoluzionarietà del nuovo sistema, poi ampiamente imitato da altri paesi e da altre mode e per la stretta relazione tra moda e società dei consumi, tra estetica e industria.
\end{abstract}

Parole chiave: eredità estetica - gusto - occidente - prêt à porter - Rinascimento - stilisti.

Summary: The return to the Renaissance -as a key of occidental speech on dressing, which resumed again during the eighties of the twentieth century to explain fashion-indicates not only an attempt to learn the history of a phenomenon that would develop later, but the need to start from a period in which Italy had the leadership of taste. It's not just the desire to return to the origins, but also to bracket an Italy that from the seventeenth century, is gradually reduced its position in Europe. During the 80's, however, the explanation of Renaissance deeply highlights, given the revolutionary new system, later imitated by other countries and other styles and by the close relationship between fashion and consumer society, between aesthetics and industry.

Keywords: aesthetic inheritance - occidental - prêt à porter - Renaissance - stylists - taste.

Resumo: O regresso ao Renascimento, fundamental de certo discurso ocidental sobre o vestir, que se retomou novamente durante os anos oitenta do século XX para explicar a moda, indica não tanto um intento por conhecer a história de um fenômeno que se de desenvolveria mais tarde, quanto a necessidade de partir de um período no qual Itália tinha a liderança do gosto. Não se trata só do desejo de voltar às origens, senão também de colocar entre parêntese uma Itália que, a partir do século XVII, vê diminuir progressivamente sua posição privilegiada na 
Europa. Durante os anos 80, sem embargo, a explicação do Renascimento ressalta particularmente, dado o caráter revolucionário do novo sistema, posteriormente imitado por outros países e outras modas e pela estreita relação entre moda e sociedade de consumo, entre estética e indústria.

Palavras chave: estilista - gosto - herança estética - ocidente - prêt à porter - Renascimento. 